friends often urged him to take a partner, but he refused to consider the suggestion on the plea that his young son, still at school, would come into the practice in due course, and that he could carry on alone until the boy was qualified to assist him.

Two years ago Clinton met with a motor accident, and those who have been most closely associated with him date the beginning of his last illness from this accident. A year ago he had a breakdown, but after a time was able to resume his work. Unfortunately there was soon a recurrence, and at the time of his death (on the 3 rd February) through an accident, he was still away from business, though he had so far progressed that, with the consent of his medical adviser, it had been definitely arranged that he should, in the following week, gradually resume his work for the Provident Association, to which he was looking forward with much satisfaction. His untimely death, however, prevented this.

Clinton was a man who set before himself the highest standard of professional conduct, and rigidly adhered to that standard. He was a good speaker with an attractive presence, and was as much at home in discussing financial problems with a Board of Directors as in addressing the members of a Friendly Society or Pension Fund and explaining to them in simple language the problems with which their Committee had to deal.

Through his death at the early age of 48 the Institute has lost an able and distinguished member, and his many friends have lost a "good companion."

H. E. M.

\title{
C. V. L. CHARLIER
}

WE record, with much regret, the death of Dr Charlier, the well-known Scandinavian physicist, astronomer and statistician. It would be inappropriate to discuss the work that probably meant most to him, but his name is familiar to actuaries and statisticians all the world over for his work on the law of error and frequency functions. Thirty years ago Charlier published in Arkiv för Matematik a paper, "Ueber das Fehlergesetz," and followed it up a year later with his well-known " Researches into the Theory of Probability" which appeared in Meddelanden frain Lunds Astronomiska Observatorium. Charlier gave two series for expressing frequency distributions; one, which he called Type A, was formed from the normal curve and its differential coefficients and was applied to bell-shaped curves with little skewness; the other, Type B, was formed from the Poisson approximation and its differences and was applied to distributions showing considerable skewness. He showed that, with the help of these two series, a very wide range of statistical examples could be satisfactorily graduated with the help of moments, 
or the equivalent half-invariants. The Type A series had been suggested long before Charlier, but for many modern workers Charlier's writings supply the best means of approach, partly because of the way they are set before the reader but chiefly because of his many arithmetical examples and his appreciation-by no means universal among writers on the subject-that a system for expressing probability distributions can only survive in practical work if it is of wide applicability and lends itself to straightforward curve-fitting. Type $B$ gave some difficulty in this last respect and has always proved rather intractable, while uncomfortable questions may arise with regard to the convergency of both series. Charlier was concerned to find a practical system and he made most skilful use of the series he advocated, but he was by no means blind to their defects, and in 1928 he produced a third series (Type C) in the hope of overcoming some of them. This series expressed the logarithm of the frequency in the form $\sum_{0}^{\infty} \gamma_{r} H_{r}(x)$, where $H_{r}(x)$ is the Hermite-polynomial of order $r$. His two examples were satisfactory, but he still seemed to prefer Type A for many purposes, and probably most practical statisticians would concur in this view.

There is one other work of Charlier's to which it is natural to referan excellent elementary little book entitled Vorlesungen ïber die Grundzïge der Mathematischen Statistik. I had the pleasure of reviewing it a dozen years ago for this fournal (F.I.A. Vol. LIV, p. 206) and I now regard it as an old friend.

Though I have never felt that series give an entirely satisfactory way of expressing frequency distributions, I have always found much pleasure in studying Charlier's work: it is so practical and is set out so well. In common with many others, I am indeed grateful to Dr Charlier for the help, interest and inspiration $I$ have found in his writings.

Professor Dr Harald Cramér has contributed the following note: "C. V. L. Charlier was born in I862 and passed the first part of his academic career at the University of Upsala, where in 1887 he became Doctor in Philosophy and was appointed as Leçurer in Astronomy. His Doctorate Dissertation (Die fupiterstörungen des Planeten Thetis), as well as a great part of his subsequent astronomical research work, was concerned with problems of celestial mechanics. As a pupil of the astronomer Gyldén he devoted himself to the study of the Problem of Three Bodies and made very valuable contributions to this subject. (In this respect, it is interesting to note that Gyldén was probably the first Swedish scientist taking an active interest in actuarial questions. He was one of the founders of the Life Assurance Company 'Thule' and made, in 1875 , the first attempt in 'Forecasting Mortality' of which I know.) 
"In 1897 Charlier was appointed Professor of Astronomy in the University of Lund. In that position he remained until 1927, when he retired. At Lund he continued and extended his astronomical work, and, beginning with the year 1906, developed his work on Mathematical Statistics. He was led to this work from the study of the distribution of the stars according to position, magnitude, velocity, etc., where he showed that important results may be obtained with statistical methods.

"His papers on purely statistical problems (A-series, correlation, etc., mainly during the years 1906-14) are well known, and I need not quote them. With respect to the applications of statistical methods to astronomical problems, his chief contributions are: Studies in Stellar Statistics, I-IV (1912-18), The Motion and Distribution of the Stars, published I926 by the University of California, and the treatise 'Applications de la théorie des probabilités à l'astronomie' (in Traité du calcul des probabilités et de ses applications, par Émile Borel), Paris I93r.

"Charlier received deep impressions from the Upsala radicalism of the 'eighties' and interested himself keenly in various political and other questions besides his scientific work. When, as a comparatively young professor, he was transferred to Lund, he was supposed by the conservatives to be a very 'dangerous' man. He has written several papers on political and economic subjects, such as Proportional Elections and Railway Tariffs.

"He had only a slight direct contact with actuarial work and the actuarial profession in Sweden. Indirectly, however, he had a great influence through his scientific work and through his pupils, several of whom are to-day well-known actuaries."

W. P. E. 